\title{
The Primary Demand for Oilseeds in South Africa: an Error Correction Linear Approximated Almost Ideal Demand System (ecm-La/aids)
}

\author{
H P van Schalkwyk, H D van Schalkwyk, Z G Alemu, P R Taljaard and A Obi
} Faculty of Natural and Agricultural Sciences, University of the Free State

\begin{abstract}
The paper presents the results of a study that estimated the demand relations for primary oilseeds in South Africa. The Error Correction version of Linear Approximated Almost Ideal Demand System (LA/AIDS) (ECM-LA/AIDS) were estimated. Time series data for the period 1971-2002 were analysed. Prior tests established weak separability between four oilseeds (sunflower seed, soybeans, groundnuts and cotton seed), indicating that these oilseeds should be modelled together. The results suggest that the demand for oilseeds is negatively influenced by own price, which is consistent with economic theory, while positive long-term expenditure elasticities suggest that some oilseeds, notably sunflower seed and cotton seed, are luxury commodities in South Africa.
\end{abstract}

JEL C32; D12

\section{1}

\section{Introduction}

Oilseeds are among the most important field crops in South Africa, subsequent to maize, wheat and sugarcane. The major oilseeds produced and utilised in the country are sunflower seed, groundnuts and soybeans. These crops are important not only in terms of the gross value of production, but also because of the significant value-added from processing into the various secondary consumer commodities. As is well known, very little of the produce is consumed in primary form. Hence the secondary effects of the processing activities impact on various sectors of the economy, especially by providing raw materials to the manufacturing and livestock feed industry.

Between 1990 and 2002, annual sunflower seed production ranged from 183,000 and 1,212,000 tonnes, while demand averaged 562,000 tonnes. Annual groundnut production ranged between 69,000 tonnes and 222,000 tonnes over the same period. In the case of soybean, although domestic production has steadily increased over the past few years (Grönum, Van Schalkwyk \& Du Plessis, 2000), fluctuating between 58,500 tonnes and 226,000 tonnes per annum since 1990, demand continues to outstrip local production. For instance, whereas the domestic market handled a total of 616,593 tonnes of soybeans in 2002, only 157,327 tonnes was produced locally.

In at least five provinces of the country, namely Gauteng, Northern Province, North West, Northern Cape and Free State Province, oilseeds account for a significant part of the gross income derived from field crops. However, despite favourable producer prices since full trade liberalisation was implemented in 1997, gross value of production for soybean and sunflower seeds fell in 2002, and was almost stagnant for groundnuts (National Department of Agriculture, 2003). It is important to investigate the reasons for this development.

Demand relations of different oilseed products have never been estimated in South Africa. Estimation of demand relations for food in aggregate predates 1987, with the bulk dating back as far as the 1970s and early 1980s. 
However, these elasticities cannot be used for predictions today, due to the far-reaching structural changes that have occurred in South Africa since that time. Furthermore, since the estimates have considered foods as a group, they cannot be expected to have much predictive value for oilseeds alone, given their peculiar production and consumption characteristics. At the same time, many of the structural changes may have had a substantial and more direct impact on the demand relations of oilseed products. It is therefore necessary to explicitly examine the demand relations for these products in order to establish more policyrelevant parameter estimates that can explain the current production situation in the subsector.

The Linear Approximated Almost Ideal Demand System (LA/AIDS) first proposed by Deaton and Meulbauer (1980), allows for the systems-wide estimation of consumer demand relations. In this study, dynamic elements were incorporated into the LA/AIDS model, based on the statistical properties of the data, and an estimation procedure referred to in the literature as ECM-LA/AIDS was thus applied in this study. Compared to the result obtained using LA/AIDS which is not reported in this study, the ECM-AIDS was found to be a superior estimation procedure for the South African oilseed data.

\section{2}

\section{Theoretical specification of the LA/ AIDS and ECM-LA/AIDS models}

The Almost Ideal Demand System (AIDS) utilises expenditure share equations which are regressed on the prices of all the commodities included in the system, as well as a common price index.

The budget share of the $\mathrm{i}^{\text {th }}$ commodity is expressed as follows:

$$
w_{i t}=\alpha_{i}+\sum_{j}^{n} \gamma_{j t} 1 \mathrm{n} p_{j t}+\beta_{i} \ln \left(X_{t} / P_{t}\right)+u_{i t}
$$

where: $i=1,2, \ldots n ; w_{i t}$ is the budget share equation of the $i^{\text {th }}$ good, $p_{j t}$ is the nominal price of the $j^{\text {th }}$ good, $L n X_{t}$ represents total expenditure and $\operatorname{Ln} P_{t}$ is the translog price index defined by: $\ln P_{t}=\alpha_{0}+\sum \alpha_{j} 1 \mathrm{n} p_{j}+\frac{1}{2} \sum_{i}^{n} \sum_{\mathrm{j}}^{n} \gamma_{i t} \ln p_{i t} 1 \mathrm{n} p_{j t}$
$\mathrm{t}=1,2, \mathrm{~T}$

As this price index makes the system nonlinear, Deaton and Meulbauer, 1980 suggested linearisation by means of the Stones price index as shown in Equation 3:

$\log P=\sum_{i=1}^{n} w_{i . t .} \log p_{i . t}$

By substituting the translog price index in the LA/AIDS model with the Stones price index and introducing a lagged budget share $\left(w_{i, t-1}\right)$ to overcome the simultaneity problem, the following properly linearised version of the AIDS system was obtained:

$$
w_{i t}=\alpha_{i}+\sum_{j}^{n} \gamma_{i j} \ln p_{j t}+\beta_{i}\left(\operatorname{Ln} X-\sum_{i=1}^{n} w_{i . t-1} \ln p_{i . t}\right)+u_{i . t}
$$

The dependant variables in the estimated equations are the expenditure shares of the individual commodities while the logarithmic prices of the individual commodities as well as a common price index are the independent variables.

To estimate an error correction (i.e. ECM) version of the LA/AIDS, or in other words what in the literature is referred to as ECM-AIDS (Karagiannis et al., 2000), both long-term and short-term equations have to be specified and estimated. Like Karagiannis et al. (2000), Equation 4 was considered as the long-term equation and was thus estimated in levels by means of ordinary least squares (OLS) to test for co-integration. The residuals term $\left(u_{i, t}\right)$ obtained from the long-term regression is saved and included in the short-term equations as an additional explanatory variable. This is done to ensure that the long-term equilibrium effects are captured, as they present the equilibrium error in the short-term model (Engle and Granger, 1987).

The short-term demand equations are estimated using Equation 5:

$$
\begin{aligned}
& \Delta w_{i t}=\sum_{j}^{n} \gamma_{i j} \Delta 1 \mathrm{n} p_{j t}+\beta_{i} \Delta\left(\operatorname{Ln} X-\sum_{i=1}^{n} w_{i, t-1}\right. \\
& \left.1 \mathrm{n} p_{i, t}\right)+\lambda_{i} u_{i, t-1}+u_{i, t}
\end{aligned}
$$


In Equation 5, $\Delta$ refers to the difference operator, $u_{i, t-1}$ are the estimated residuals from co-integrating equations, and $\lambda_{i}<0$. The demand restrictions tested and imposed on the short-term equations include:

Homogeneity:

$\sum \gamma_{i j}=0$

Adding up:

$\sum_{i} \alpha_{i}=1, \sum_{i} \gamma_{i j}=0, \sum_{i} \beta_{i}=0$

Symmetry:

$\gamma_{i j}=\gamma_{j i}$

The homogeneity and symmetry restrictions were tested using the Wald test statistics in the Micro Fit 4.1 package.

Compensated and uncompensated price elasticities were derived using Equation 9 and 10 respectively:

$e_{i, t} *=e_{i t}+\hat{\beta}\left(\frac{\bar{w}_{j}}{\bar{w}_{i}}\right)=-\delta+\frac{\hat{y}}{w_{t}}+\bar{w}_{j} \mathrm{i}, \mathrm{j}=1,2, \ldots, \mathrm{n}$

$e_{i, t}=-\delta+\frac{\hat{y}_{i t}}{\bar{w}_{t}}-\hat{\beta}_{t}\left(\frac{\bar{w}_{j}}{\bar{w}_{i}}\right)$

where $d=1$ for $i=j$ and $d=1$, otherwise. The average expenditure shares are represented by $\bar{w}_{t}$, whereas $\hat{\beta}_{t} \hat{\gamma}_{i t}$, are the parameter estimates of the co-integration equations (long-term). The formula, taken from Jung (2000) for calculating expenditure elasticities, can be written as:

$\eta_{1}=1+\frac{\beta_{i}}{\bar{w}_{i}}$

\section{3 \\ Statistical tests and transformations}

Before estimating the model, the variables were subjected to four statistical tests, namely: univariate properties (i.e. stationarity or nonstationarity) of the data, structural breaks, separability and exogeneity of the expenditure variable. As these tests afford unique insights into the statistical properties of the data, the next sections are devoted to a brief discussion of their theoretical bases and the procedures involved.

\subsection{Stationarity of the variables}

Most econometric modelling makes use of economic data in the estimation of various relationships. The reality is that the majority of these economic variables are connected in many different ways. In order to capture and account for these occurrences, it is necessary to ensure the stationarity of all the variables included in the system of demand equations. A series is said to be stationary if the residual (error term) obtained by estimating that equation has an expected value of zero $\left(E\left(u_{t}\right)=0\right)$, and fluctuations around its mean value are not growing or declining over time i.e. constant variance $\left(E\left(u_{t}^{2}\right)=\sigma^{2}\right)$. In the event of non-stationarity, the series can be rendered stationary by differencing, although some information about the long term may be lost (Studenmund, 2001).

\subsection{Structural breaks}

Newbold, Rayner and Kellard (2000) developed a systematic method to identify and capture structural breaks that may occur in a dataset. According to Alemu, Oosthuizen and Van Schalkwyk (2003), such breaks are caused by adverse policy situations or natural calamities, making it desirable to detect and evaluate the associated exogenous variables and to ensure structural stability within the system. The procedure is to plot the residuals of the estimated budget share equations within twostandard error bands. The structural breaks coincide with the points where the plotted residuals fall outside the standard error bands. Correction is achieved by introducing dummy variables that are then tested for significance.

\subsection{Separability}

The purpose here is to determine whether or not the commodities can be modelled together. In order to estimate a demand system, commodities included in the system should belong to the same group from a two-stage budgeting procedure. This will depend on the extent to which the demand for, and expenditure on, one commodity is influenced by the situation with respect to other commodities in the group. 
Following Deaton and Meulbauer (1999) and Jung (2000), it is said that a two-stage budgeting procedure occurs under which consumers allocate total expenditure in two stages, firstly to broad groups of goods (food, shelter and entertainment), and then to individual commodities within each group (see Figure 1). The two-stage budgeting process of household disposable income enables us to establish the inter-relatedness of commodities implied by this test (see Jung, 2000 and also Deaton \& Meulbauer, 1999). Separability requires that the marginal rate of substitution between any two variables belonging to the same group be independent of the value of any variable in any other group (Phlips, 1974). A necessary and sufficient condition for the second stage of the two-stage budgeting procedure is weak separability of the utility function over broad groups of goods (Jung, 2000).

\section{Figure 1}

Schematic representation of the two-stage budgeting process

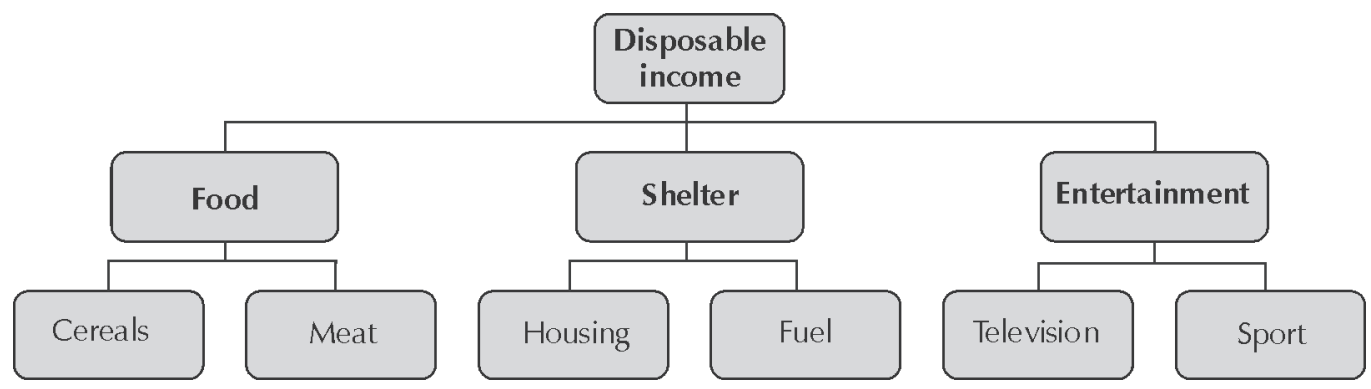

Source: Deaton and Meulbauer, 1999

\subsection{Exogeneity of the expenditure variable}

It is necessary to test for exogeneity of the expenditure variable $(\mathrm{X})$ in each of the budget shares to establish that it is not correlated with the random error term, a situation that would produce biased parameter estimates (Edgerton, 1993). This study followed the suggestion of LaFrance (1991) to apply the Hausman test written as:

$m=T\left(\theta^{*}-\theta\right)^{\prime}\left[\operatorname{Var}\left(\theta^{*}\right)-\operatorname{Var}(\theta)\right]^{-1}\left(\theta^{*}-\theta\right) \quad 12$

\section{4}

\section{The data and statistical properties}

\subsection{The data}

Time series data on consumption, own prices and expenditures for the four principal oilseeds, namely groundnuts, sunflower seeds, soybean and cotton seed, were obtained for the period 1971 to 2002. The main source of the data is the latest edition of the Abstracts of Agricultural
Statistics published by the National Department of Agriculture (NDA). The data relate to the primary products as distinct from the processed products, which are the common focus of empirical analysis in South Africa.

\subsection{Statistical properties of the data}

The prior statistical tests performed on the data provided useful insights into the nature of the data used and the type of transformation necessary to incorporate the data into the specified models.

\subsubsection{Stationarity of the variables}

The Dickey-Fuller (DF) and Augmented Dickey-Fuller (ADF) tests for stationarity were performed on the data. Table 1 presents the DF and ADF test statistics for all the variables included in the demand analysis. The variables were tested as is and in first differences according to the following hypothesis:

$\mathrm{H}_{\mathrm{o}}$ : The series is stationary

$\mathrm{H}_{\mathrm{A}}$ : The series is non-stationary 
The decision rule is that if the calculated DF and ADF statistics are smaller than the 95 per cent critical value, then the series is said to be non-stationary; if otherwise, then stationary. The statistics depicted in Table 1 indicate that the variables used in the demand analysis are integrated of order one I(1), meaning that the variables will become stationary after first differencing.

\section{Table 1}

Test statistics for unit roots in variables

\begin{tabular}{|c|c|c|c|c|c|}
\hline \multirow{2}{*}{$\begin{array}{l}\text { Variables } \\
\text { in levels }\end{array}$} & \multicolumn{2}{|c|}{ Intercept } & \multirow{2}{*}{$\begin{array}{l}\text { Variables in } \\
\mathbf{1}^{\text {st }} \text { difference }\end{array}$} & \multicolumn{2}{|c|}{ Intercept } \\
\hline & DF & ADF & & DF & ADF \\
\hline WCS & -3.562 & -2.623 & DWCS & -13.166 & -8.447 \\
\hline WSF & -2.428 & -1.667 & DWSF & -8.582 & -5.281 \\
\hline WSB & -1.691 & -1.604 & DWSB & -5.483 & -5.666 \\
\hline WGN & -3.944 & -.3 .341 & DWGN & -12.961 & -7.961 \\
\hline LNPCS & -1.215 & -1.525 & DLNPCS & -7.913 & -5.739 \\
\hline LNPSF & -0.513 & -0.501 & DLNPSF & -4.421 & -8.375 \\
\hline LNPSB & -1.214 & -1.495 & DLNPSB & -7.532 & -6.191 \\
\hline LNPGN & -1.201 & -1.027 & DLNPGN & -7.469 & -4.364 \\
\hline EXP & -2.593 & -2.071 & DEXP & -7.409 & -5.856 \\
\hline $\begin{array}{l}95 \% \text { critical } \\
\text { value }\end{array}$ & -2.9627 & & $\begin{array}{l}95 \% \text { critical } \\
\text { value }\end{array}$ & -2.9665 & \\
\hline
\end{tabular}

\subsubsection{Structural breaks}

With regard to the existence of structural breaks, the residual plot of sunflower seeds shows a break in 1981. This is probably due to the bumper crop in South Africa in 1980, when sunflower production was 59.1 per cent higher than in 1979.

The residual plot for the soybean budget share equation identified a possible structural break for 1997. A possible explanation for the dummy variable included for 1997 can be attributed to the deregulation of the South African Agriculture sector after 1994. The oilseeds marketing board governing soybeans was finally abolished at the end of September 1997. This might be the explanation for the structural break in the soybeans budget share equation in 1997.

The residual plot of the groundnuts budget share equation also indicates a structural break in 1973. South Africa experienced severe drought conditions in the early 1970s, and that is reflected in the producer sales of groundnuts, which decreased from 183,431 tonnes in 1972 to 128,264 in 1973.
In all three cases mentioned, there were noticeable swings towards the end of the series in 2002, although in no case did the residual plots exceed the standard error bands. However, it is important to note the separate regional developments from 2001, featuring extensive and prolonged droughts and other humanitarian crises, culminating in severe famine in many countries of Southern Africa. The fact that the gross value of production for soybean and sunflower seeds fell in 2002 and was almost stagnant for groundnuts (NDA, 2003), seems an important finding which needs to be examined alongside other results of this analysis.

\subsubsection{Separability}

The commodities included in this study are included as primary products and the demand for the products is derived from the demand for oilseeds from processors, who process them to obtain oilcakes for the animal feed industry and oils for human and industrial use. 
The two tests for weak separability, namely the F-test and the Likelihood Ratio test, failed to reject the null hypothesis of weak separability among the commodities. Table 2 below presents the results of the separability tests. As the results show, in seven out of nine cases, significant tests were obtained. These results therefore confirm that the four oilseeds are separable from other commodities and should be modelled together.

Table 2

Calculated f-statistics to test for separability

\begin{tabular}{|l|c|c|c|c|}
\hline \multirow{2}{*}{$\begin{array}{l}\text { Dependant } \\
\text { variable }\end{array}$} & \multicolumn{2}{|c|}{ Price variable dropped for testing } \\
\cline { 2 - 5 } & Cotton & Soybeans & Sunflower & Groundnuts \\
\hline DWSF & $2.74^{*}$ & $3.38^{*}$ & - & $6.97^{*}$ \\
\hline DWSB & 0.07 & - & $2.55^{*}$ & $1.89^{*}$ \\
\hline DWGN & $5.72^{*}$ & 0.31 & $2.43^{*}$ & - \\
\hline 95\% Critical value & 1.708 & & & \\
\hline
\end{tabular}

* Significance at $5 \%$ level

\subsubsection{Exogeneity of the expenditure variable}

The results of the exogeneity test presented in Table 3 show that all the calculated $m$ values for the oilseeds under consideration are smaller than the critical Chi-squared values with five degrees of freedom at 5 per cent level of significance. This indicates that the expenditure variables tested are indeed exogenous, and ensures that the Seemingly Unrelated Regression method for estimating the LA/AIDS will indeed provide the best linear unbiased estimators (BLUE).

\section{Table 3}

Exogeneity test of the expenditure variable $(\mathrm{Df}=5)$

\begin{tabular}{|l|c|c|}
\hline & Calculated statistic & Critical value $(\alpha=\mathbf{0 . 0 5})$ \\
\hline Sunflower & 3.34961 & 11.07 \\
\hline Soybeans & 0.02518 & 11.07 \\
\hline Groundnuts & 4.97932 & 11.07 \\
\hline System & 8.35412 & 33.21 \\
\hline
\end{tabular}

\subsubsection{Homogeneity and symmetry of the demand function}

Table 4 presents the results of the Wald test for homogeneity and symmetry of the demand function. Two null hypotheses that the logarithmic prices included in the equations are homogenous of degree zero and that they are symmetric were tested. The chance of committing an error when rejecting the null hypothesis in the case of the ECM model is at least 16 per cent, and it can be concluded with a reasonable level of confidence ( 84 per cent) that the prices are homogeneous of degree zero and symmetric, indicating that the sum of the prices in a single equation is equal to 0 , and that the cross-price coefficients are equal. This critically important testing procedure of the demand restrictions, which was previously neglected, ensures that the estimated parameters and associated elasticities will be consistent with economic theory of consumer demand. 


\begin{tabular}{|c|c|}
\hline \multicolumn{2}{|c|}{$\begin{array}{l}\text { Table } 4 \\
\text { Wald statistics for testing the homogeneity } \\
\text { and symmetry restrictions }\end{array}$} \\
\hline Restriction & $\begin{array}{l}\text { Wald test } \\
\text { statistic } \\
\text { P-Value }\end{array}$ \\
\hline Homogeneity in: & \\
\hline Sunflower share equation & $\begin{array}{l}1.9607 \\
0.161\end{array}$ \\
\hline Soybeans share equation & $\begin{array}{l}0.1643 \\
0.685\end{array}$ \\
\hline Groundnuts share equation & $\begin{array}{l}0.5770 \\
0.447\end{array}$ \\
\hline Symmetry for: & \\
\hline $\begin{array}{l}\text { Sunflower and soybeans price } \\
\text { parameters }\end{array}$ & $\begin{array}{l}1.3672 \\
0.242\end{array}$ \\
\hline $\begin{array}{l}\text { Sunflower and groundnuts price } \\
\text { parameters }\end{array}$ & $\begin{array}{l}0.0049 \\
0.944\end{array}$ \\
\hline $\begin{array}{l}\text { Soybeans and groundnuts price } \\
\text { parameters }\end{array}$ & $\begin{array}{l}0.4971 \\
0.481\end{array}$ \\
\hline
\end{tabular}

\section{5 \\ Results and discussion}

The ECM-LA/AIDS Model enables the estimation of short-term elasticities of demand once the equilibrium of the static (long-term) equations have been tested and confirmed. The formula for calculating the own-price, crossprice and expenditure elasticities are the same as in the case of the LA/AIDS model reported in Equations 9 to 11 and were therefore used to calculate the elasticities as well as the associated variances to determine their significance (Karagiannis et al., 2000). The long-term elasticities are calculated by using the same formulas, but the parameter estimates of the co-integration equations were used instead (Johnson, Oksanen, Veall \& Fretz, 1992).

\subsection{Calculated long-term elasticities}

Table 5 presents the long-term expenditure and compensated own-price elasticities of sunflower seeds, soybeans, groundnuts and cotton seeds calculated based on results reported in Appendix 1. The compensated own-price elasticities, which indicate the substitution effect of a change in price, are all negative, as expected from economic theory, but the ownprice elasticities of sunflower seed and soybeans are not significant at the 95 per cent level of confidence. The long-term expenditure elasticities are positive, and sunflower seed and cotton can be seen as luxury goods, with their calculated expenditure elasticities being greater than one.

The long-term compensated own-price elasticity of seed cotton is greater than one, indicating that cotton is relatively more elastic in the long term, that is, the change in the quantity demanded is greater than the change in the price of the commodity.

Table 5

Long-term expenditure and compensated own-price elasticities

\begin{tabular}{|l|c|c|c|c|}
\hline Elasticity & Sunflower & Soybeans & Groundnuts & Cotton \\
\hline $\begin{array}{l}\text { Own-price } \\
\text { elasticity }\end{array}$ & $\begin{array}{c}-0.013 \\
(-0.378)\end{array}$ & $\begin{array}{c}-0.047 \\
(-0.440)\end{array}$ & $\begin{array}{r}-0.717^{*} \\
(-18.344)\end{array}$ & $\begin{array}{c}-1.181^{*} \\
(-21.483)\end{array}$ \\
\hline $\begin{array}{l}\text { Expenditure } \\
\text { elasticity }\end{array}$ & $\begin{array}{c}1.064^{* *} \\
(79.744)\end{array}$ & $\begin{array}{c}0.824 \\
(22.448)\end{array}$ & $\begin{array}{r}0.785^{*} \\
(26.494)\end{array}$ & $\begin{array}{c}2.839^{*} \\
(33.891)\end{array}$ \\
\hline
\end{tabular}

* Significance at 5 per cent, t-ratios in parentheses

\subsection{Calculated short-term elasticities}

The ECM-LA/AIDS model was fitted and thus short-term elasticities were calculated after equilibrium and the static (long-term) equations have been tested and confirmed as shown in Appendix 2. Le Chatelier's principle states that, in the case of long-term equilibrium, the long-term compensated own-price elasticities should be larger than the short-term compensated own-price elasticities (Milgrom \& Roberts, 1996). From Table 6, which summarises the ECM-LA/AIDS model shown in Appendix 3, it can be seen that the shortterm compensated own-price elasticities with 
respect to groundnuts and cotton, are less than their long-term counterparts. The own-price elasticities of sunflower and soybeans are smaller (less elastic) in the long term than in the short term but, as mentioned earlier, neither of them is significant at the 5 per cent level of significance.

Table 6

Short-term compensated elasticities of oilseeds in South Africa

\begin{tabular}{|l|c|c|c|c|}
\hline & Sunflower & Soybeans & Groundnuts & Cotton \\
\hline Sunflower & $-0.164^{*}$ & 0.001 & 0.004 & $0.429^{*}$ \\
\hline Soybeans & $(-6.925)$ & $(0.012)$ & $(0.134)$ & $0.111^{*}$ \\
\hline & 0.000 & $-0.666^{*}$ & $0.160^{*}$ & 0.001 \\
\hline Groundnuts & $(0.003)$ & $(-14.550)$ & $(13.252)$ & $-0.165^{*}$ \\
\hline & 0.002 & $0.415^{*}$ & $(-6.087)$ & $-0.542^{*}$ \\
\hline Cotton seed & $(0.134)$ & $(13.252)$ & 0.001 & \\
\hline & $0.162^{*}$ & $0.252^{*}$ & $(0.059)$ & \\
\hline
\end{tabular}

* Significance at the 5 per cent level, t-ratios are in parentheses

The uncompensated own-price and cross-price elasticities, which include both the income and substitution effects of a change in price, are shown in Table 7. In terms of statistical significance, the elasticities calculated from the estimated EC model are more reliable, with all 16 elasticities being significant at the 95 per cent level of confidence.

Table 7

Short-term uncompensated elasticities of oilseeds in South Africa

\begin{tabular}{|l|c|c|c|c|}
\hline & Sunflower & Soybeans & Groundnuts & Cotton \\
\hline Sunflower & $-0.723^{*}$ & $-0.250^{*}$ & $-0.450^{*}$ & $-0.109^{*}$ \\
\hline Soybeans & $(-29.681)$ & $(-4.378)$ & $(-13.679)$ & $0.021^{*}$ \\
\hline & $-0.093^{*}$ & $-0.707^{*}$ & $0.084^{*}$ & $(6.896)$ \\
\hline Groundnuts & $(-9.944$ & $(-15.444)$ & $-0.361^{*}$ & $-0.231^{*}$ \\
\hline & $-0.240^{*}$ & $0.307^{*}$ & $(-13.070)$ & $-0.745^{*}$ \\
\hline Cotton seed & $(-17.833)$ & $(9.690)$ & $-0.170^{*}$ & $(-8.541)$ \\
\hline
\end{tabular}

* Significance at 5 per cent, t-ratios in parentheses

The estimated short-term expenditure elasticities of the ECM-LA/AIDS Model indicated that sunflower seed and cotton can be regarded as luxury commodities, with elasticities of 1.105 and 1.064 respectively. The elasticities, presented in Table 8, are all positive as expected, with the expenditure elasticities of the three estimated equations all being significant. According to Wold and Juréen (1962), sunflower seed, groundnuts and cotton can further also be classified as luxury products, with their expenditure elasticities being greater in absolute terms than their compensated ownprice elasticities. 
Table 8

Short-term expenditure elasticities of oilseeds in South Africa

\begin{tabular}{|l|c|c|c|c|}
\hline & Sunflower & Soybeans & Groundnuts & Cotton \\
\hline Expenditure & $1.105^{*}$ & $0.493^{*}$ & $0.897^{*}$ & 1.064 \\
\hline & $(93.769)$ & $(21.676)$ & $(37.254)$ & \\
\hline
\end{tabular}

* Significance at 5 per cent, t-ratios in parentheses

6

\section{Conclusion}

This paper deals with the specification and estimation of the ECM version of LA/AIDS, which allowed for the estimation of short- and long-term elasticities of demand for primary oilseeds for the first time in South Africa.

The results revealed negative long-term ownprice elasticities for all the oilseeds in their primary forms. This observation is consistent with economic theory, suggesting inverse relationships between the prices and quantities demanded for all the commodities. However, the long-term own-price elasticities of sunflower seed and soybeans were not significant at the 95 per cent level of confidence, which could mean a weak price effect on demand. The long-term expenditure elasticities are positive, and sunflower seed and cotton can be seen as luxury goods with the calculated expenditure elasticities being greater than one. The long-term compensated own-price elasticity of seed cotton is greater than one, indicating that cotton is relatively elastic in the long-term, that is, the change in the quantity demanded is greater than the change in the price of the commodity.

It is therefore highly unlikely that higher producer prices due to market liberalisation are responsible for the reduced gross value of production observed in 2002, at least in the case of soybean and sunflower seeds. The fact that the apparent reduction in the gross value of production of oilseeds in 2002 coincided with the severe famines which ravaged most countries in Southern Africa could be a possible explanation. The analysis did not provide evidence of a structural break in the series for the year 2002, and this means that we must be careful in allocating a weight to the observed reductions in the gross value of production for the commodities. However, the important regional developments, beginning in 2001, need to be noted. Most of the countries in the region suffered severe food shortages due to the prolonged droughts which resulted in crop failures in consecutive years. As is well known, most of them depend on South Africa for the augmentation of their domestic food supplies. It is possible that, in response to growing regional demand for emergency food assistance, farmers in South Africa switched investment out of oilseeds into food grains.

Another phenomenon influencing the demand for oilseeds is the international growth in palm oil production. The world production of palm oil increased by 336 per cent between 1980 and 2000, whereas South Africa's palm oil imports grew by 53 per cent from 1998 to 2002. Some of the reasons for this growth include the leveraging of techno-economic advantages of palm oil vis-á-vis competing oils, global developments in terms of health and the environment as well as security of supply. Palm oil is highly price competitive and output rarely declines due to climatic constraints. The major market for palm oil is in the developing countries, where it has the image of a 'poor man's oil'.

While these responses and global phenomena can be anticipated and are easily modelled, they were not examined in this study and may be important elements of future research in the context of the impact of liberalisation and other regional socio-political, economic, and climatic developments. As the famine situation begins to stabilise, it will be interesting to see how the oilseed sub-sector reacts before any definitive conclusions can be drawn. However, this situation could well point up the precarious position of the oilseeds vis-à-vis the other field crops, and the need to explicitly model regional 
developments to understand how they affect domestic supply.

\section{Endnote}

The authors would like to thank Dr. A. Obi and two anonymous referees for their constructive comments and suggestions.

\section{References}

1 ALEMU, Z.G.; OOSTHUIZEN, L.K. \& VAN SCHALKWYK, H.D. (2003) "Contribution of agriculture in the Ethiopian economy. A timevarying parameter approach”, Agrekon, 42(1): 29-48.

2 DEATON, A. \& MUElBAUER, J. (1980) "An almost ideal demand system", The American Economic Review, 70(3): 312-26.

3 DEATON, A. \& MUELBAUER, J. (1999)

"Economics and consumer behavior", University Press: Cambridge.

4 EDGERTON, D.L. (1993) "On the estimation of separable demand models", Journal of Agricultural and Resource Economics, 18(2): 6279.

5 ENGLE, R.F. \& GRANGER, C.W.F. (1987)

"Co-integration and error correction:

Representation, estimation and testing", Econometrica, 55(2): 251-76.

6 GRÖNUM, C.F.; VAN SCHALKWYK, H.D. \& DU PLESSIS, J.H. (2000) "The comparative advantage of dryland soybean production in Brits, North West", Agrekon, 39(3).

7 JOHNSON, J.; OKSANEN, E.; VEALL, M. \& FRETZ, D. (1992) "Short-term and long-term elasticities for Canadian consumption of alcoholic beverages: An error correction mechanism/co-integration approach", The Review of Economics and Statistics, 74(1): 64-74.

8 JUNG, J. (2000) "Econometric estimation of demand for meat and fish products in Korea", unpublished MS thesis, North Dakota State University: Fargo.

9 KARAGIANNIS, G.; KATRANIDIS, S. \& VELENTZAS, K. (2000) "An error correction almost ideal demand system for meat in Greece", Agricultural Economics, 22: 29-35.

10 LAFRANCE, J.T. (1991) "When is expenditure "exogenous" in separable demand systems", Western Journal of Agricultural Economics, 16(1): 49-62.

11 MILGROM, P. \& ROBERTS, J. (1996) "The LeChatelier Principle”, The American Economic Review, 86(1): 173-9.

12 NATIONAL DEPARTMENT OF AGRICULTURE (2003) Abstracts of Agricultural Statistics, RSA.

13 NEWBOLD, P.; RAYNER, T. \& KELLARD, N. (2000) "Long-term drift, co-movement and persistence in real wheat and maize prices", Journal of Agricultural Economics, 51(1): 10621.

14 PHLIPS, L. (1974) Applied Consumption Analysis, North-Holland Publishing Company: Amsterdam.

15 STUDENMUND, A.H. (2001) Using Econometrics: A Practical Guide, Addison Wesley Longman, Inc: Boston.

16 WOLD, H. \& JURÉEN, L. (1962) Demand Analysis: A Study in Econometrics, Wiley and Sons: New York. 


\section{Appendix 1: Long-term parameter estimates}

\begin{tabular}{|l|l|c|c|c|c|}
\hline & \multicolumn{5}{|c|}{ Dependent variable } \\
\hline \multirow{4}{*}{$\begin{array}{l}\text { Explanatory } \\
\text { variables }\end{array}$} & Sunflower & $\begin{array}{c}0.24332^{* * *} \\
(2.4519)\end{array}$ & $\begin{array}{c}-0.014641 \\
(-0.32262)\end{array}$ & $\begin{array}{c}-0.092153 \\
(-0.96980)\end{array}$ & $\begin{array}{c}-0.21035^{* *} \\
(-1.6910)\end{array}$ \\
\cline { 2 - 6 } & Soybeans & $\begin{array}{c}-0.19948^{* *} \\
(-1.7877)\end{array}$ & $\begin{array}{c}0.078962^{* *} \\
(1.5474)\end{array}$ & $\begin{array}{c}-0.031938 \\
(-0.29892)\end{array}$ & $\begin{array}{c}0.28672^{* * *} \\
(2.1248)\end{array}$ \\
\cline { 2 - 6 } & Groundnuts & -0.056146 & -0.023427 & $0.14061^{* * *}$ & -0.068877 \\
& & $(-1.1130)$ & $(-1.0154)$ & $(2.9108)$ & $(-1.0319)$ \\
\cline { 2 - 6 } & Cotton & 0.12002 & 0.022511 & -0.10153 & -0.071057 \\
& & $(0.99230)$ & $(0.40698)$ & $(-0.87662)$ & $(-0.44597)$ \\
\cline { 2 - 6 } & Expenditure & 0.032629 & -0.014788 & -0.046959 & 0.035143 \\
& $(0.85342)$ & $(-0.84574)$ & $(-1.2827)$ & $(0.69434)$ \\
\hline
\end{tabular}

T-ratios in parentheses. ${ }^{*}$ indicates significance at $10 \%, * *$ indicates significance at $5 \%$,

*** indicates significance at $1 \%$

\section{Appendix 2: Test results on co-integration}

\begin{tabular}{|l|c|}
\hline Residuals tested for stationarity & Calculated ADF(1) statistic \\
\hline Sunflower share equation & -3.2793 \\
\hline Soybean share equation & -3.3624 \\
\hline Groundnuts share equation & -3.8551 \\
\hline $95 \%$ critical value & -2.9627 \\
\hline
\end{tabular}

\section{Appendix 3: Parameter estimates of the ECM-LA/AIDS Model}

\begin{tabular}{|c|c|c|c|c|}
\hline \multicolumn{5}{|c|}{ Dependent variable } \\
\hline & Sunflower & Soybeans & Groundnuts & Cotton \\
\hline Sunflower & $\begin{array}{l}0.16710^{* * *} \\
(2.5083)\end{array}$ & & & \\
\hline Soybeans & $\begin{array}{l}-0.04268^{* *} \\
(-1.6259)\end{array}$ & $\begin{array}{c}0.021044 \\
(0.98127)\end{array}$ & & \\
\hline Groundnuts & $\begin{array}{l}-0.10970^{* * *} \\
(-2.9512)\end{array}$ & $\begin{array}{l}0.016520 \\
(1.1265)\end{array}$ & $\begin{array}{l}0.13467^{* * *} \\
(4.0845)\end{array}$ & \\
\hline Cotton & $\begin{array}{l}-0.014721 \\
(-0.33692)\end{array}$ & $\begin{array}{c}0.005113 \\
(0.24008)\end{array}$ & $\begin{array}{l}-0.041485^{* *} \\
(-1.7589)\end{array}$ & 0.0511 \\
\hline Expenditure & $\begin{array}{l}0.053013^{* *} \\
(1.5961)\end{array}$ & $\begin{array}{l}-0.042678^{* * *} \\
(-4.0039)\end{array}$ & $\begin{array}{l}-0.022545 \\
(-0.77015)\end{array}$ & 0.0122 \\
\hline Residual(-1) & $\begin{array}{l}-0.66161^{* * *} \\
(-5.2845)\end{array}$ & $\begin{array}{c}-0.18968^{*} \\
(-1.4413)\end{array}$ & $\begin{array}{l}-0.24348^{* *} \\
(-2.3190)\end{array}$ & \\
\hline Dummy1973 & & & $\begin{array}{c}-0.41601^{* * *} \\
(-10.4921)\end{array}$ & \\
\hline Dummy1974 & & & $\begin{array}{l}0.25481^{* * *} \\
(6.2923)\end{array}$ & \\
\hline Dummy1997 & & $\begin{array}{l}0.6985^{* * *} \\
(3.0026)\end{array}$ & & \\
\hline
\end{tabular}

T-ratios in parentheses. $*, * *$, and $* * *$ indicate significance respectively at $10 \%, 5 \%$ and $1 \%$ 